\title{
Study on GMZ bentonite-sand mixture by undrained triaxial tests
}

\author{
Wen-jing Sun ${ }^{1,2, a}$, Chao Chen ${ }^{1}$, Shi-qing Liu ${ }^{1}$, De-an Sun ${ }^{1}$, Xue-hai Liang ${ }^{1}$, Yun-Zhi $\operatorname{Tan}^{3}$ and Behzad Fatahi ${ }^{4}$ \\ ${ }^{1}$ Civil Engineering Department, Shanghai University, Shanghai, 200444, China \\ ${ }^{2}$ State Key Laboratory of Geomechanics and Geotechnical Engineering, Institute of Rock and Soil Mechanics, Chinese Academy of \\ Sciences, Wuhan 430071, China \\ ${ }^{3}$ College of civil engineering \& architecture, China Three Gorges University, Yichang, 443002, China \\ ${ }^{4}$ Centre for Built Infrastructure Research, School of Civil and Environmental Engineering, Faculty of Engineering and IT, University of \\ Technology, Sydney, 15 Broadway, Ultimo, NSW2007, Australia
}

\begin{abstract}
It is particularly necessary to study the deformation, strength and the changes of pore water pressure of bentonite-based buffer/backfill materials under the undrained condition. A series of isotropic compression tests and triaxial shear tests under undrained conditions were conducted on the compacted saturated/unsaturated GMZ bentonite-sand mixtures with dry mass ratio of bentonite/sand of 30:70. During the tests, the images of the sample were collected by photographic equipment and subsequently were cropped, binarized and centroids marked by image processing technique. Based on identification of the variation of the position of marked centroids, the deformation of the sample can be determined automatically in real-time. Finally, the hydro-mechanical behaviour of saturated and unsaturated bentonite-sand mixtures under the undrained condition can be obtained. From results of triaxial shear tests on unsaturated samples under constant water content, inflated volumetric deformation transforms to contractive volumetric deformation due to the increase of the confining pressure and lateral expansion deformation are observed due to the increase in the shearing stress. Moreover, the net mean stress affects the initial stiffness, undrained shear strength and deformation of the sample during the undrained shear tests.
\end{abstract}

\section{Introduction}

Currently, it is widely accepted that the deep geological disposal is the feasible solution for the disposal of high-level radioactive wastes [1]. The project adopts the multiple engineering barrier system, and respectively from the inside to the outside are waste storage containers, engineered barrier based on the bentonite and the surrounding rock geological barrier. Addition of a certain proportion of the quartz sand to bentonite can efficiently enhance the overall thermal conductivity, the mechanical strength and long-term stability ([2], [3], [4]).

Because of bentonite's low hydraulic conductivity, the unsaturated bentonite-sand mixture can be considered in an undrained condition during construction and in-service stages of deep geological repository. During undrained shearing process, the negative pore water pressure is produced in soil. With the passage of time, the pressure will dissipate gradually, and the strength of bentonite-sand mixture will correspondingly decreases, which brings the potential hazards to deep geological disposal project. Therefore, it is particularly necessary to study the hydro-mechanical behaviour on bentonite-sand mixtures under the undrained condition.

In recent years, several researchers have conducted some research about hydro-mechanical behaviour of unsaturated soils under constant water content using triaxial test. Rahardjo et al. studied the strength characteristics of compacted residual soils [5]. Thu et al. investigated the variation of shear strength and pore pressure of compacted kaolin soil [6]. Chen et al. studied the suction and mechanical properties of unsaturated undisturbed loess at constant moisture content triaxial condition [7]. However, the triaxial test results on unsaturated bentonite-based materials under constant water content are relatively small which might be due to the availability of testing apparatus and long duration of triaxial tests on unsaturated bentonite-based materials.

This paper aims to study the hydro-mechanical properties of bentonite-sand mixture used in the deep geological disposal project at the undrained condition through triaxial isotropic compression and triaxial shear tests. During the tests, the images of the sample were collected by photographic equipment and subsequently the deformation of the sample could be determined automatically in real-time by image processing technique. Through the undrained triaxial tests, the variation of deformation, strength and pore water pressure of saturated and unsaturated bentonite-sand mixtures could be obtained under undrained condition. The tests provide

\footnotetext{
${ }^{\text {a }}$ Corresponding author: wjsun@shu.edu.cn
} 
parameters and data to the model which is capable of predicting the coupled hydro-mechanical behaviour of unsaturated expansive soils under both drained and undrained conditions.

\section{Testing program}

\subsection{Testing materials}

According to the performance analysis, GMZ sodium bentonite produced in the Inner Mongolia autonomous region is considered for using as a matrix material of engineered barrier in deep geological disposal system in China because of its high swelling property, low hydraulic conductivity, good self-sealing capacity, and excellent radionuclide sorption property [8].

In the tests conducted in this study, GMZ07 Na-bentonite was used, and Fujian standard sand was also included. The Fujian standard sand was firstly seived to reserve the sand particles with the size between 0.074 $\mathrm{mm}$ and $0.5 \mathrm{~mm}$. The main physical parameters of GMZ07 bentonite and seived Fujian standard sand are listed in Table 1.The samples, $50 \mathrm{~mm}$ in diameter and 100 $\mathrm{mm}$ in height, were prepared by compaction in a mold at certain initial water content and dry density, where the ratio of bentonite/sand in terms of mass was 30:70.The deionized water was used during the tests to minimize the influence of ion exchange on the hydro-mechanical behaviour because of bentonite's very high cation exchange capacity.

Table1. Properties of GMZ 07-Na bentonite and Fujian standard sand

\begin{tabular}{lclc}
\hline GMZ07-Na & Index & Fujian Sand & Index \\
\hline$G_{s}$ & 2.76 & $G_{s}$ & 2.65 \\
$w_{L}(\%)$ & 125 & $D_{50}(\mathrm{~mm})$ & 0.34 \\
$w_{P}(\%)$ & 30 & $C_{u}$ & 1.97 \\
$I_{p}$ & 95 & & \\
\hline
\end{tabular}

$G_{s}:$ Specific grativity; $w_{\mathrm{L}}$ : Liquid limit; $w_{\mathrm{P}}$ : Plastic limit; $I_{\mathrm{P}}$ : Plastic index; $D_{50}$ : Average diameter; $C_{\mathrm{u}}$ : Uniformity coefficient.

\subsection{Test apparatus \& deformation measurement method}

The unsaturated/saturated triaxial test apparatus adopting digital image measurement method is shown in Figure 1. The apparatus was modified on the basis of a triaxial test apparatus for saturated soils, adding an air pressure controller, and replacing the original pedestal of the cell with a new one with a high air entry value ceramic disk. In order to measure the volume change of sample during consolidation and shearing precisely, a digital image measurement system, designed and developed at the State Key Laboratory of Structural Analysis for Industrial Equipment at Dalian University of Technology, based on the sub-pixel accurate corner locator was used to measure the strain of sample ([9],[10]). The system consisted of a complementary metal-oxide-semiconductor (CMOS) digital photographic camera $(1280 \times 1024$ pixels $)$ containing the USB2.0 data interface, $16 \mathrm{~mm}$ prime lens, and the image processing software. The digital camera model was DH-HV03 manufactured by China Daheng (Group) Co., Ltd. with advantages of high accuracy, high resolution, and low noise characteristics. In order to facilitate the acquisition and analysis of images, the inner-wall of triaxial cell was painted black with LED lights placed at the top and bottom. A black rubber membrane was used to insulate soil from water and the white square marks were printed on its surface.

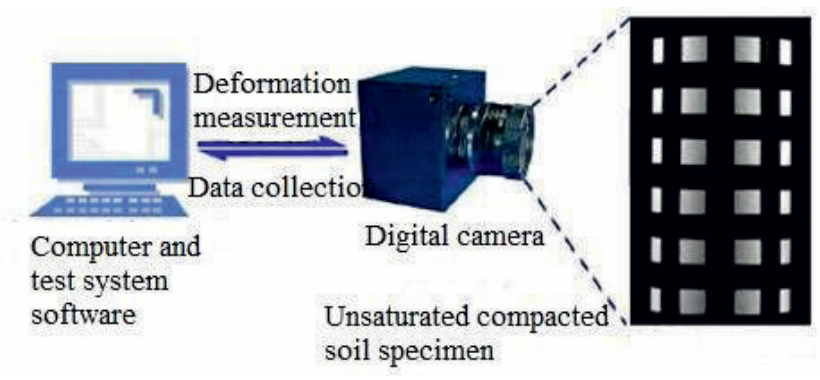

(a) Digital image measurement system [9]
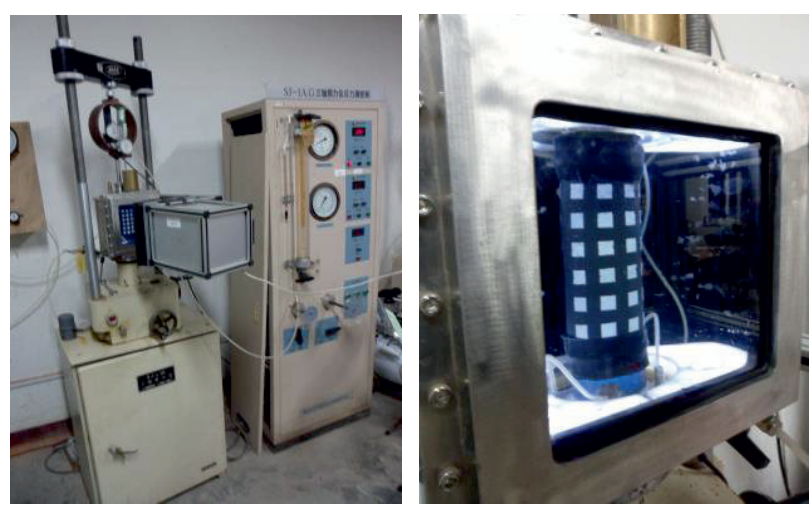

(b) Modified triaxial apparatus and cell

Fig.1 Triaxial test apparatus of unsaturated/saturated soil

Advantages of this digital image measurement technology include noncontact measurements, minimal disturbance to samples, and high accuracy [9]. When installing the sample, the sample wrapped with membrane must be kept upright. Moreover, those four columns and middle six lines as a total of 24 white square marks printed on the surface of membrane should be located in the central picture area, as shown in Figure 1. During the process of consolidation and shearing, the images of the unsaturated/saturated samples were collected by photographic equipment. Subsequently, the images were cropped, binarized and centroids marked by image processing technique, as shown in Figure 2. The marked centroids as well as coordinates were expressed as $c_{i j}\left(x_{i j}, y_{i j}\right)$, where $i=1,2,3,4,5,6 ; j=1,2,3,4$. The deformation of the sample could be determined based on identification of the variation of the position of marked centroids. 


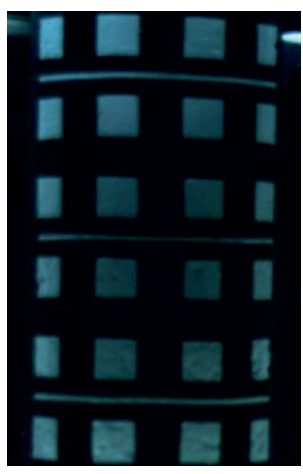

Initial

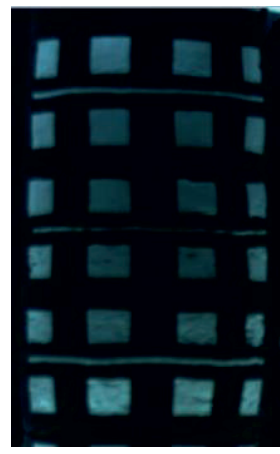

Time $\mathrm{t}$ (a) Images after cropped

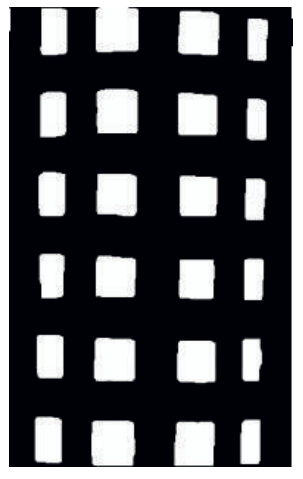

Initial

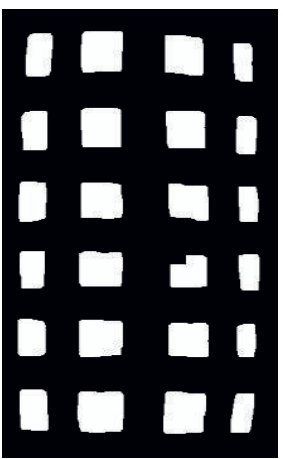

Time $\mathrm{t}$

(b) Images after binarized

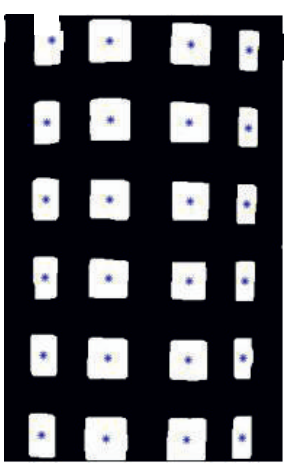

Initial

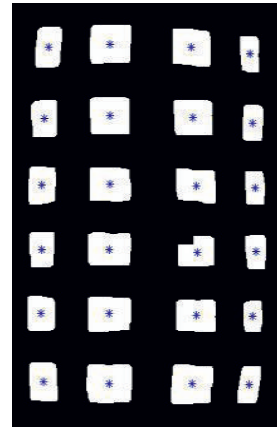

Time $\mathrm{t}$ (c) Images after centroids marked

Fig.2 Image processing

Parts of the collected images were selected and the pixel coordinates of marked points on the images were expressed to determine the centroids' distribution. Then the axial and radial strains of the sample could be calculated according to the pixel coordinates of centroids at each moment. The collected pictures reflected the projection of three-dimensional entity. After the transformation of pixel coordinates, the radial strain of samples could be calculated using the similar triangle principle, as shown in Figure 3. In Figure 3, $r$ is the initial radius of the sample, $R$ is the radius of the sample at time $t$, $\mathrm{a}$ is the initial radial projection length, $\mathrm{b}$ is the radial projection length at time $t, x_{i 1}$ and $x_{i 4}$ are the horizontal data of centroids at the first and the fourth columns. The transformation process of radial strain from initial to time $t$ can be expressed by Eq. (1).

$$
\varepsilon_{r}=(R-r) / r=(b-a) / a
$$

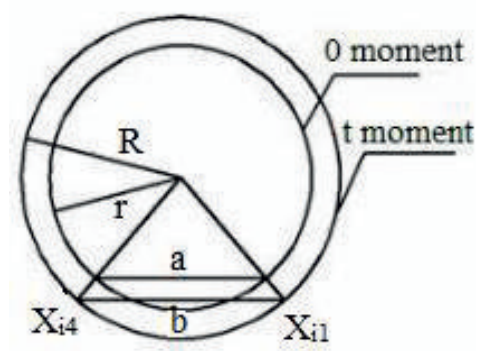

Fig.3 Sketch of change in samples cross section

Figure 4 illustrates the distribution of the centroid location during the triaxial shearing test. The strain calculation process is as follows [9]:

The axial average strain $\varepsilon_{a}{ }^{t}$ at time $t$ is:

$$
\varepsilon_{a}^{t}=\frac{1}{m} \sum_{j=1}^{m} \frac{\left(y_{6 j}^{0}-y_{1 j}^{0}\right)-\left(y_{6 j}^{t}-y_{1 j}^{t}\right)}{\left(y_{6 j}^{0}-y_{1 j}^{0}\right)}
$$

where $m$ is the numbers of columns of marked points in the axial direction, $m=4, y_{6 j}$ and $y_{1 j}$ are the vertical coordinate values of centroids at the sixth line and the first line.

The radial average strain $\varepsilon_{r}^{t}$ at time $t$ is:

$$
\varepsilon_{r}^{t}=\frac{1}{n} \sum_{i=1}^{n} \frac{\left(x_{i 4}^{0}-x_{i 1}^{0}\right)-\left(x_{i 4}^{t}-x_{i 1}^{t}\right)}{\left(x_{i 4}^{0}-x_{i 1}^{0}\right)}
$$

where $n$ is the numbers of rows of marked points in the radial direction, $n=6, x_{i 4}$ and $x_{i 1}$ are the horizontal data of centroids at fourth column and the first column.

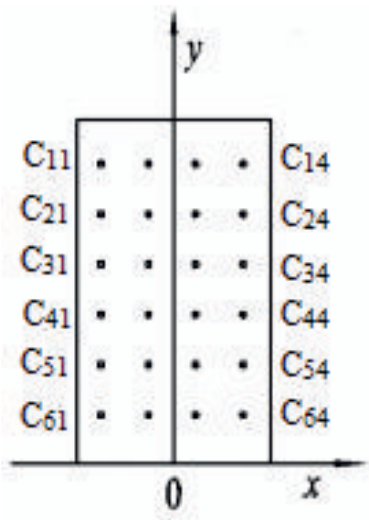

(a) Initial

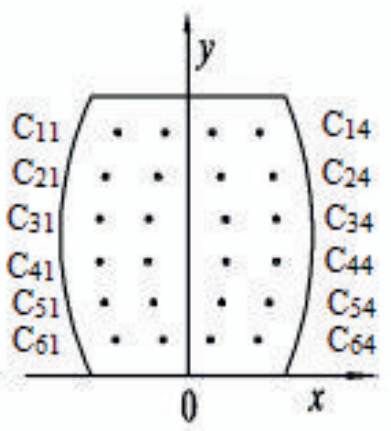

(b) Time $\mathrm{t}$
Fig.4 Sketch of deformation and distribution of centroid location during triaxial shearing test. 
To verify the accuracy of the obtained strains using image processing technology, an auxiliary dial indicator was also used in the process of shearing. Figure 5 shows the comparisons of the axial strain measured by the image processing and by the dial indicator. It can be seen that the results are in good agreement, which testified the feasibility of applying digital image measurement technology for the deformation measurement in the triaxial tests.

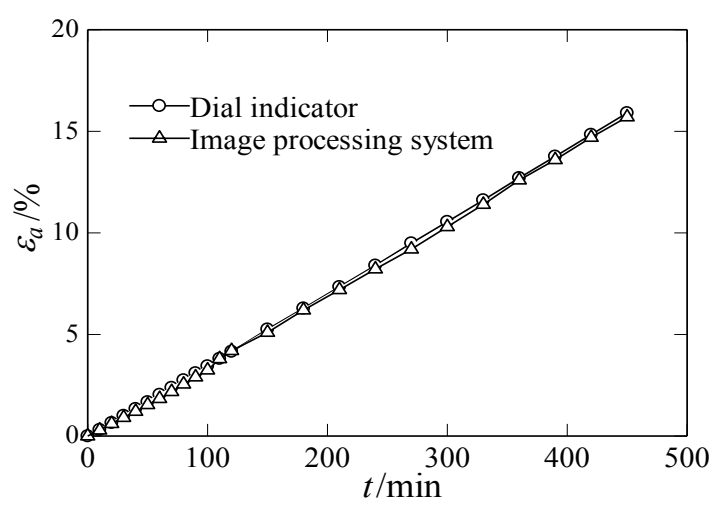

Fig.5 Comparisons of axial strain results measured by dial indicator and image processing

\section{Testing result and analysis}

The six samples, No.1-No.6, were firstly compressed isotropically under undrained condition. After compression test, undrained triaxial shear tests were carried out under constant net confining pressure with the axial shear rate of $0.033 \mathrm{~mm} / \mathrm{min}$. The state parameters on samples No.1-No.6 in the tests are listed in Table 2.
No.1-No.4 samples were in the unsaturated state with initial water content of $17.6 \%$ and the initial suction of $150 \mathrm{kPa}$ measured by the filter paper method [11]. The undrained shear tests under the net confining pressure of50, 100, 200 and $400 \mathrm{kPa}$ were conducted respectively. The pore air pressures applied on No.1-No.3 samples were kept constant at $300 \mathrm{kPa}$, however, the air pressure was controlled at $150 \mathrm{kPa}$ for No.4 sample because the maximum pressure burdened by the cell was less than $600 \mathrm{kPa}$. From Table 2, it can be seen that the void ratio decreases after isotropic compression, and the suction decreases due to the increasing of degree of saturation and the decreasing of void ratio. Moreover, the suction reduction increases with the net confining pressure.

Figure 6 shows the stress-strain behaviour of four unsaturated samples (No.1-No.4) in the undrained triaxial shear tests under the net confining pressure of $50 \mathrm{kPa}, 100$ $\mathrm{kPa}, 200 \mathrm{kPa}$ and $400 \mathrm{kPa}$ respectively. It can be observed that the $q-\varepsilon_{a}$ curves of samples No.2-No.4 under the net confining pressure of $100 \mathrm{kPa}, 200 \mathrm{kPa}$ and $400 \mathrm{kPa}$ show the hardening behaviour, while the deviatoric stress stabilizes after $10 \%$ axial strain for No.1 sample under the net confining stress of $50 \mathrm{kPa}$. The strength, hardening degree and the initial stiffness of samples increase with the net confining pressure. This is due to the fact that the structure of unsaturated soil sample gradually degrades with the increase of net confining pressure and the decrease of the suction. In the process of shearing, all samples produce lateral expansion deformation that increases with the net confining pressure. Moreover, from the $\varepsilon_{a}-\varepsilon_{v}$ curve, it is evident that shear dilatancy occurs under the net confining pressure of $50 \mathrm{kPa}$, and the volumetric change converts from shear dilatancy to shear shrinkage when the net confining pressure increases to $100 \mathrm{kPa}, 200 \mathrm{kPa}$ and $400 \mathrm{kPa}$, simultaneously the volume contraction increases with the net confining pressure.

Table2 .State properties of samples in undrained triaxial tests

\begin{tabular}{|c|c|c|c|c|c|c|c|c|c|c|c|}
\hline \multirow{3}{*}{ No. } & \multicolumn{3}{|c|}{ Initial state } & \multicolumn{3}{|c|}{ After compression } & \multicolumn{3}{|c|}{ After shearing } & \multirow{3}{*}{$\begin{array}{c}\mathrm{u}_{a} \\
/ \mathrm{kPa}\end{array}$} & \multirow{3}{*}{$\begin{array}{c}\sigma_{3 \mathrm{n}} \\
/ \mathrm{kPa}\end{array}$} \\
\hline & $w_{0}$ & $s_{0}$ & \multirow[b]{2}{*}{$e_{0}$} & $\overline{s_{\mathrm{c}}}$ & & $S_{r \mathrm{C}}$ & $\overline{s_{\mathrm{s}}}$ & \multirow[b]{2}{*}{$e_{\mathrm{s}}$} & $S_{r s} d$ & & \\
\hline & $/ \%$ & $/ \mathrm{kPa}$ & & $/ \mathrm{kPa}$ & $e_{\mathrm{c}}$ & $\%$ & $/ \mathrm{kPa}$ & & $\%$ & & \\
\hline 1 & 17.7 & 150 & 0.80 & 132 & 0.80 & 60.30 & 84 & 0.83 & 56.85 & 300 & 50 \\
\hline 2 & 17.5 & 150 & 0.80 & 127 & 0.79 & 59.97 & 68 & 0.76 & 61.46 & 300 & 100 \\
\hline 3 & 17.7 & 150 & 0.79 & 122 & 0.77 & 62.67 & 56 & 0.72 & 66.28 & 300 & 200 \\
\hline 4 & 17.7 & 150 & 0.79 & 90 & 0.75 & 63.14 & 56 & 0.66 & 71.64 & 150 & 400 \\
\hline 5 & 29.6 & 0 & 0.85 & 0 & 0.84 & 94.51 & 0 & 0.82 & 96.81 & 0 & 100 \\
\hline 6 & 29.7 & 0 & 0.85 & 0 & 0.83 & 95.83 & 0 & 0.82 & 97.14 & 0 & 200 \\
\hline
\end{tabular}

Note: $w_{0}, e_{0}, s_{0}, S_{r 0}$-initial water content, void ratio, suction, degree of saturation; $e_{\mathrm{c}}, s_{\mathrm{c}}, S_{r \mathrm{c}}$-void ratio, suction, degree of saturation after compression; $e_{\mathrm{s}}, s_{\mathrm{s}}, S_{r \mathrm{~s}}$-void ratio, suction, degree of saturation after shearing; $\sigma_{3}$ - total confining pressure; $u_{a}-$ pore air pressure; $\sigma_{3 n}$-net confining pressure. 


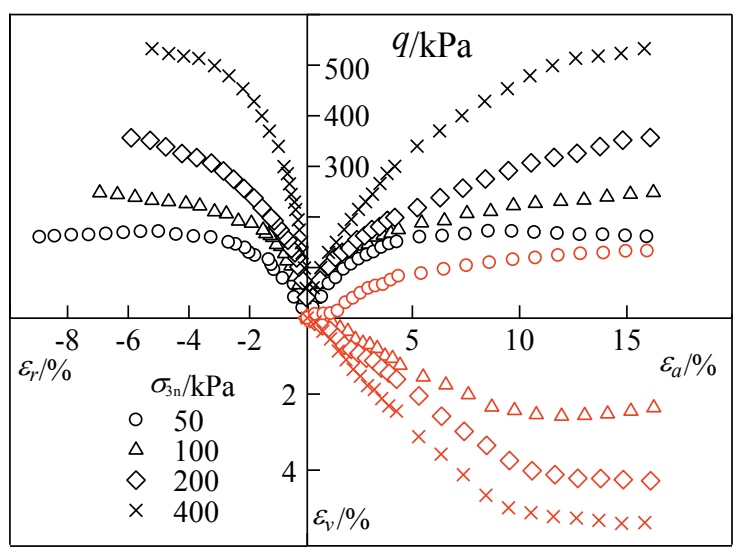

Fig.6 Stress-strain relations of unsaturated samples in constant water content triaxial shear tests

The void ratio and suction decrease after the isotropic compression for four unsaturated samples No.1-No.4 with almost the same initial state, as shown in Table 2. During the undrained shear test, the hydro-mechanical properties of the unsaturated samples also change, as shown in Figure 7. Figure 7(a) shows the variation of the suction and degree of saturation while Figure 7(b) shows the relationship between deformation and average net stress. It can be observed that the void ratio and suction decrease and the degree of saturation increases with the shear stress under the net confining pressure of $100 \mathrm{kPa}$, $200 \mathrm{kPa}$ and $400 \mathrm{kPa}$. The dilatancy deformation occurs and the degree of saturation decreases for sample No.1 under the net confining pressure of $50 \mathrm{kPa}$. Moreover the suction decreased and stabilized after $10 \%$ axial strain.

In order to determine the shear strength of saturated soil samples and compare with the results of undrained triaxial test of unsaturated soil samples, the undrained triaxial tests at the confining pressure of $100 \mathrm{kPa}$ and $200 \mathrm{kPa}$ were carried out on the two saturated samples No. 5 and No.6 respectively. The state parameters of samples No.5-No.6 in the tests are summarized in Table 2.

Figure 8 shows the Mohr circles and shear strength envelopes obtained from undrained triaxial shear tests. Considering the variation of pore water pressure of samples during the undrained shear tests, the average skeleton stress is adapted in horizontal axis. The average skeleton stress is defined as:

$$
\sigma^{\prime}=\sigma-u_{a}+S_{r} s
$$

where $\sigma$ is the total stress, $u_{a}$ is the pore air pressure, $\sigma$ $u_{a}$ is the net stress, $S_{r}$ is the degree of saturation, and $s$ is the suction. The unconsolidated undrained triaxial tests on saturated samples were conducted, so the shear failure envelope was a horizontal line, and the undrained shear strength $\tau_{f}$ of saturated sample was $34.5 \mathrm{kPa}$. The internal friction angle $\varphi$ of unsaturated GMZ Na bentonite - sand mixture with a sand content of $70 \%$ was $21^{\circ}$ according to the shear failure envelope of the unsaturated samples.

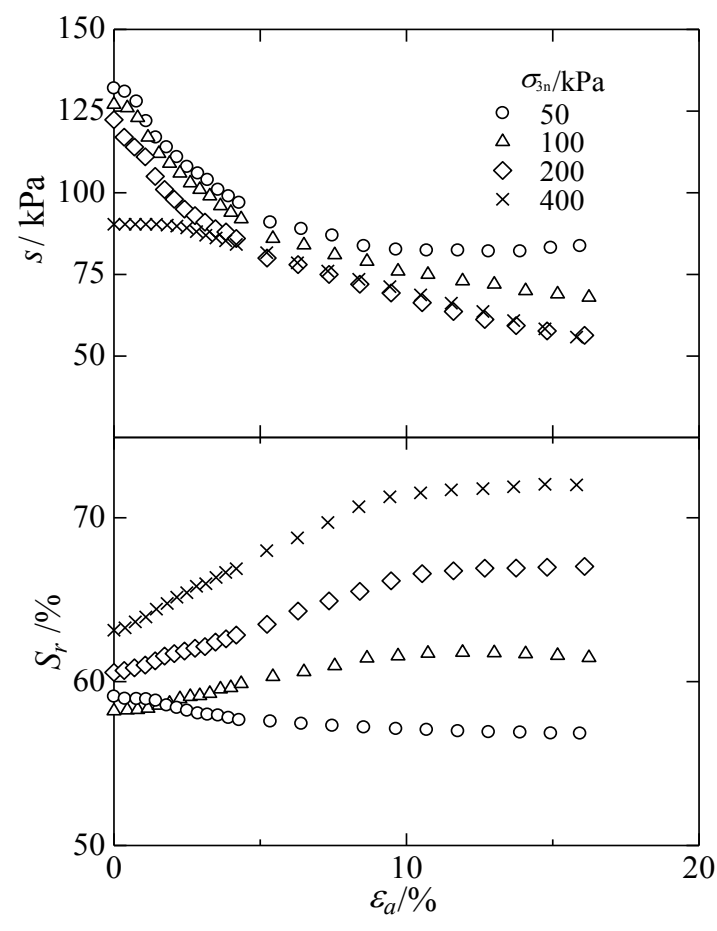

(a) $s-\varepsilon_{a} \& S_{r}-\varepsilon_{a}$

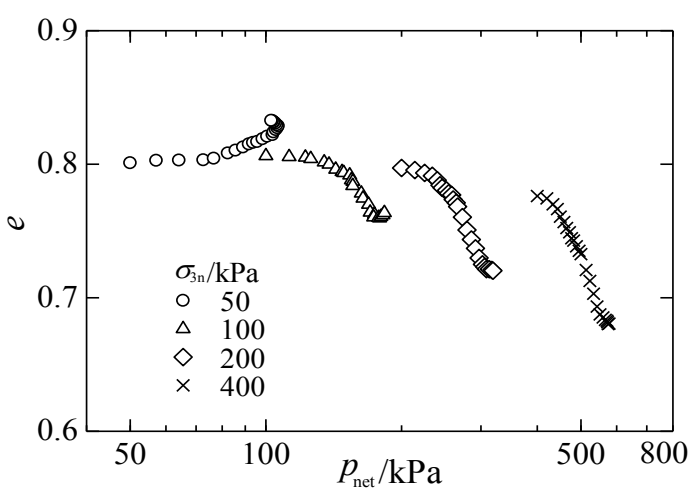

(b) $e-p_{\text {net }}$

Fig.7 Hydro-mechanical behaviour in undrained triaxial shear tests

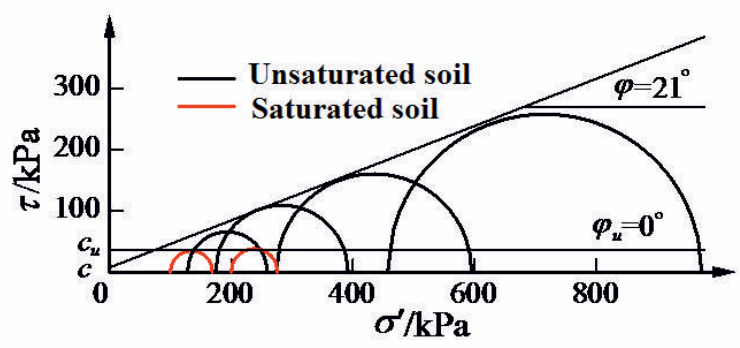

Fig.8 Mohr's stress circles and strength envelopes for unsaturated and saturated samples 
Figure 9 depicts the stress-strain curve of unsaturated and saturated samples under the same net confining pressure $\left(\sigma_{3 n}=100 \mathrm{kPa}\right)$. It can be concluded that, the shear strength of unsaturated sample is higher than that of saturated sample under the same net confining pressure. This is because the air in the unsaturated sample is compressed or partially dissolved in water during shearing, which subsequently increases the shear strength of unsaturated soil sample.

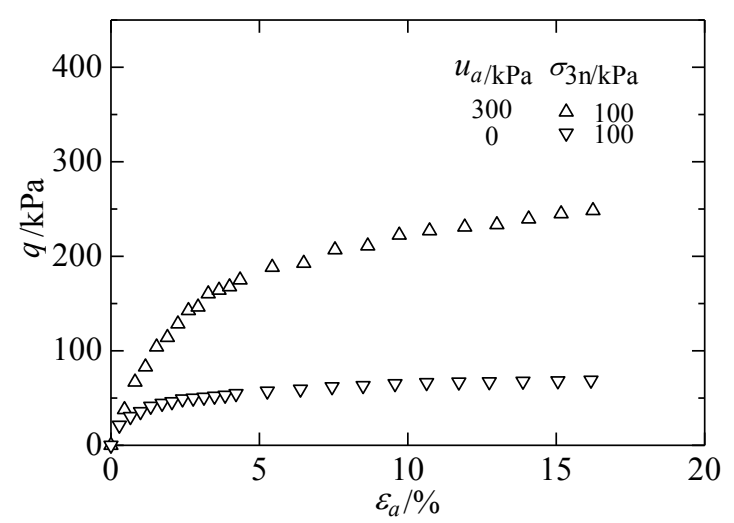

Fig.9 Stress-strain curves of saturated and unsaturated sample at the same net confining pressure

\section{Conclusions}

A series of undrained isotropic compression tests and undrained triaxial shear tests were conducted on GMZ bentonite-sand mixture with $70 \%$ sand content, and the strength, deformation and hydro-mechanical characteristics were measured and the following conclusions could be drawn:

1) After the undrained compression tests on unsaturated soil samples, the void ratio and suction decrease, while the rate of change increases with the net confining pressure.

2) In the undrained triaxial shear test, the undrained shear strength increases with the net confining pressure, and the shear strength of unsaturated sample is higher than that of saturated sample under the same net confining pressure.

3) Lateral expansion can be observed during the undrained shear tests, and the inflated volumetric deformation converts to the contractive one with the increase of the net confining pressure.

\section{Acknowledgements}

The authors appreciate the financial support of the National Sciences Foundation of China (Grant No. 41102163, 41572284) and the Open Research Fund of State Key Laboratory of Geomechanics and Geotechnical Engineering, Institute of Rock and Soil Mechanics, Chinese Academy of Sciences (Grant No. Z013008)

\section{References}

1. KASAM, Nuclear waste, state-of-the-art reports. (2001)

2. Chapuis.R.P, Sand-bentonite liners. Can Geotech J. 27 (1): 47-57(1990)

3. Kenney.T, Vanveen.W, Swallow.M, Sungaila.M. Can Geotech J. 29(3): 364-374.(1992)

4. Chen Y.G, Ye W.M,Wang Q, Chen B. Eng Geol. 18 (3): 357-362.(2010)

5. Rahardjo H, Heng O B, Leong E C. Can Geotech J. 41(3): 421-436.(2004)

6. Thu T M, Rahardjo H, Leong E C. J Geotech Geoenviron.132(3): 411-419.(2006)

7. Chen C.L, Zhang D.F, Dong Y.Z, Chen H, Yu D. B, Xue J.X. J Geotech Geoenviron.36(7): 1195-1202. (in Chinese, 2014)

8. Wen Z.J. Acta Geologica Sinica (English Edition). 82(5): 1050-1055.(2008)

9. Shao L.T, Wang Z.P, Han G.C, et al. Chinese Journal of Geotechnical Engineering. 23(3): 337-341. (in Chinese, 2001)

10. Sang Y, Shao L.T, Guo X.X, Huang C. Instrum Sci Technol. 43:429 - 445, (2015)

11. Sun D.A, Meng D.L, Sun W.J, et al. Rock Soil Mech. 32(4): 973-978 (in Chinese, 2010) 